\title{
Experimental Study on Heat Transfer and Resistance Characteristics of H-type Finned Tube
}

\author{
Heng Chen, Qinxin Zhao, Yungang Wang, \\ Haidong Ma, Yuxin Li, Zhongya Chen \\ Key Laboratory of Thermo-Fluid Science and Engineering (Ministry of Education), \\ Xi'an Jiaotong University, \\ Xi'an, 710049, China
}

\begin{abstract}
The heat exchanger element H-type finned tube has a high enhancement of heat transfer and excellent self-cleaning property and has evident effect in the boiler renovation, especially in the field of flue gas waste heat recovery. In this paper, the heat transfer and resistance characteristics of $\mathbf{H}$ type finned tube are studied by the experimental system of open high-temperature wind tunnel. The effects of fin width, fin height, fin pitch and air velocity on fin efficiency, convective heat transfer coefficient and pressure drop are examined. It is found that as air velocity, fin height and fin width increase, fin efficiency decreases. Convective heat transfer coefficient is proportional to fin pitch but inversely proportional to fin height and fin width. Pressure drop increases with the increase of fin height and fin width. Then the correlations of fin efficiency, $\mathrm{Nu}$ and $\mathrm{Eu}$ are fitted.
\end{abstract}

Keywords-waste heat recover; heat transfer, resistance; H-type finned tube

\section{INTRODUCTION}

In order to improve the efficiency of heat exchanger, extend surface heat transfer part H-type finned tubes have wildly used in boilers and waste heat recovery in recent years. H-type finned tube is derived, in large part, from the rectangle-type finned tube. Because of its unique groove structure in fin surface, H-type finned tube has excellent anti-wear and anti-fouling performance [1].

At present, a lot of experimental and numerical studies have been conducted on heat transfer and resistance characteristics of finned tubes. However, most of these studies focus on spiral finned tube, plain finned tube and serrated finned tube. There is less literature about the heat transfer and resistance characteristics of $\mathrm{H}$-type finned tube.

Tong [2], Zhang et al. [3] and Yu et al. [1] studied heat transfer and pressure drop characteristics of H-type finned tube bank by numerical simulation. The effects of geometric parameters and Reynolds number were examined. Yu et al. [4], Han-Taw and Jian-Rong [5] and $\mathrm{Wu}$ et al. [6] performed experimental tests to the heat transfer and resistance characteristics of H-type finned tube bank and provided some reference for the design of H-type finned tube bundle. Due to restricted experimental conditions and different fin structures, most research is limited to single factor experiments, and the obtained experimental correlations are limited, which cannot fully explain how the factors synthetically effect the heat transfer and pressure drop. Because of different test conditions, the results of $\mathrm{H}$ type finned tube's heat exchange coefficient and resistance coefficient are quite different. So it necessary to carry out comprehensive experiment research on the heat transfer and resistance characteristics of $\mathrm{H}$-type finned tube.

In this paper, an open high-temperature wind tunnel is applied to study the heat transfer and pressure drop characteristics of H-type finned tubes with different fin pitch $P$, fin height $h_{1}$ and fin width $h_{2}$. The relations between convective heat transfer coefficient $\alpha$, fin efficiency $\eta$ and resistance coefficient $E u$ and air velocity $v$, fin pitch $P$, fin height $h_{1}$ and fin width $h_{2}$ are studied. Then the correlations of convective heat transfer coefficient $\alpha$, fin efficiency $\eta$ and resistance coefficient $E u$ are fitted. The research could provide some theoretical basis for heat transfer and resistance characteristics of H-type finned tube and an important reference for its engineering application.

\section{EXPERIMENTAL}

\section{A. Experimental setup}

Experiments were carried out in an open hightemperature wind tunnel with heating and cooling systems, as shown in Figure 1. The heating system includes a draft fan, an air heater and an air temperature controller. The cooling system consists of a circulating Heat Transfer Fluid (HTF) tank, volume flow meters, a pump and valves. The test section is $2 \times 2$ in-line $\mathrm{H}$-type finned tube bank.

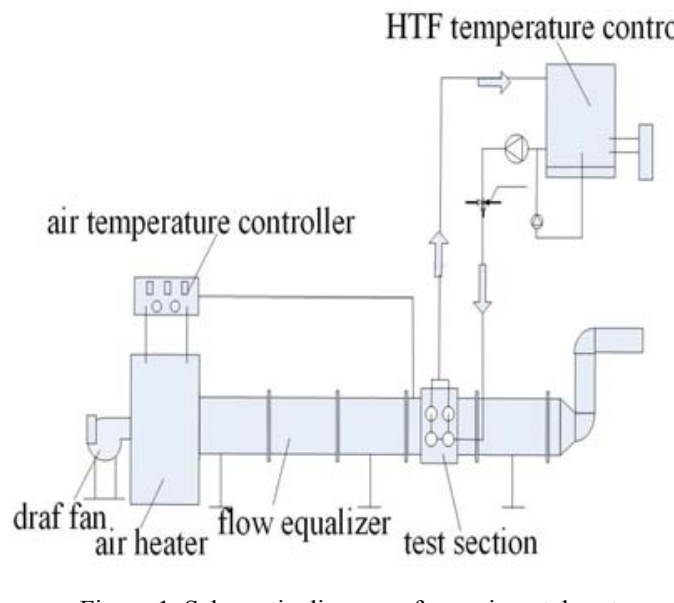

Figure 1. Schematic diagram of experimental system 


\section{B. Experimental method}

The heat transfer and resistance characteristics of H-type finned tube were studied by varying air velocity $v$, fin pitch $P$, fin height $h_{1}$ and fin width $h_{2}$.

The physical meaning of fin efficiency $\eta_{\mathrm{f}}$ is the ratio of the actual heat transfer and the given heat transfer assuming that the fin surface temperature is equal to that of the base tube. The relation of fin efficiency $\eta_{\mathrm{f}}$ and fin structure, material and heat transfer conditions can be expressed as:

$$
\eta_{\mathrm{f}}=f\left(\frac{h_{1}}{d}, \frac{h_{2}}{d}, v\right)
$$

Where $h_{1}=$ fin height; $h_{2}=$ fin width; $v=$ average air velocity of the test section.

According to Eqn. 1, fin efficiency $\eta_{\mathrm{f}}$ can be derived by measuring the fin temperatures of different H-type finned tubes. Then the correlation of fin efficiency is fitted.

When air flows across the H-type finned tube bank, its heat transfer and pressure drop are effected by a lot of factors such as fluid velocity, bank arrangement, tube pitch, tube structure, tube number and air characteristic.

To facilitate experimental data processing, convective heat transfer coefficient $\alpha$ is expressed as:

$$
\alpha=\phi\left(v, h_{1}, h_{2}, P, \rho, \lambda, c_{p}, v\right)
$$

The resistance characteristic of H-type finned tube can be described by a dimensionless criterion $E u$ :

$$
E u=\frac{2 \Delta p}{\rho v^{2}}
$$

Where $\Delta p=$ the pressure drop of the tube bank;
By varying air velocity $v$ of the test section, pressure drop $\Delta p$ of the test section ban be measured to fit $E u$ 's correlation:

$$
E u=A\left(\frac{l}{d_{\mathrm{d} l}}\right)^{m} R e^{B}
$$

\section{Experimental conditions}

Air velocity $v$ of the test section was set as $6 \mathrm{~m} / \mathrm{s}, 8 \mathrm{~m} / \mathrm{s}$, $10 \mathrm{~m} / \mathrm{s}, 12 \mathrm{~m} / \mathrm{s}$ and $15 \mathrm{~m} / \mathrm{s}$. The structure of H-type finned tube is shown in Figure 2. Six types of H-type finned tubes with different structures were tested, as shown in Table I.

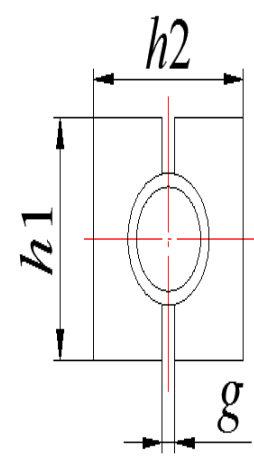

\begin{tabular}{|c|c|c|c|c|c|c|c|}
\hline Parameter & Nomen-clature & $\begin{array}{l}\text { Type } \\
\text { A }\end{array}$ & $\begin{array}{l}\text { Type } \\
\text { B }\end{array}$ & $\begin{array}{l}\text { Type } \\
\text { C }\end{array}$ & $\begin{array}{l}\text { Type } \\
\text { D }\end{array}$ & $\begin{array}{l}\text { Type } \\
\text { E }\end{array}$ & $\begin{array}{l}\text { Type } \\
\text { F }\end{array}$ \\
\hline Tube diameter & $D$ & 38 & 38 & 38 & 38 & 38 & 38 \\
\hline Tube thickness & $t$ & 4 & 4 & 4 & 4 & 4 & 4 \\
\hline Fin height & $h_{1}$ & 89 & 89 & 89 & 90 & 90 & 90 \\
\hline Fin width & $h_{2}$ & 95 & 95 & 95 & 105 & 105 & 105 \\
\hline Slit width & $g$ & 13 & 13 & 13 & 13 & 13 & 13 \\
\hline Fin thickness & $\delta$ & 2.5 & 2.5 & 2.5 & 2.5 & 2.5 & 2.5 \\
\hline Fin pitch & $P$ & 12.7 & 19.05 & 25.4 & 12.7 & 19.05 & 25.4 \\
\hline
\end{tabular}

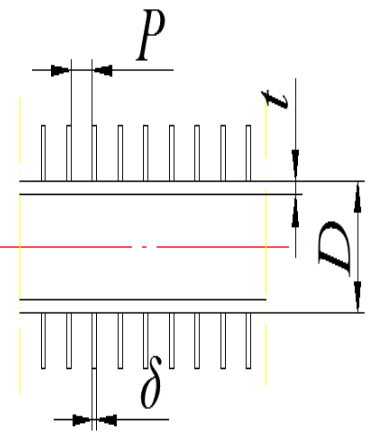

Figure 2. Structure of H-type finned tube

TABLE I. TYPES OF H-TYPE FINNED TUBE

Unit: $\mathrm{mm}$

\section{RESULTS AND DISCUSSION}

\section{A. Experimental results}

- Fin efficiency $\eta_{\mathrm{f}}$

The relation between fin efficiency $\eta_{\mathrm{f}}$ and air velocity $v$ is shown in Figure 3. As air velocity, fin height and fin width increase, fin efficiency decreases. Fin pitch has little effect on fin efficiency. So fin efficiency is primarily associated with air velocity, fin height and fin width. 


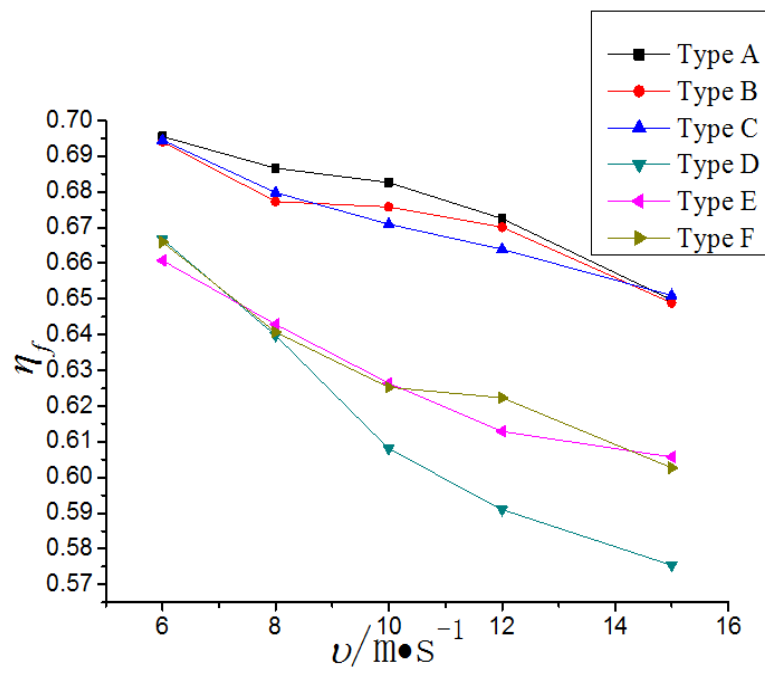

Figure 3. Relation between fin efficiency $\eta_{\mathrm{f}}$ and air velocity $v$

- Convective heat transfer coefficient $\alpha$

The relation between convective heat transfer coefficient $\alpha$ and air velocity $\mathrm{v}$ is shown in Figure 4 . With the same fin pitch, convective heat transfer coefficient $\alpha$ decreases with the increase of fin height and fin width. With the same fin height and fin width, as fin pitch increases, convective heat transfer coefficient $\alpha$ increases and the effect of fin pitch on convective heat transfer coefficient $\alpha$ becomes less. Therefore convective heat transfer coefficient $\alpha$ is proportional to fin pitch but inversely proportional to fin height and fin width.

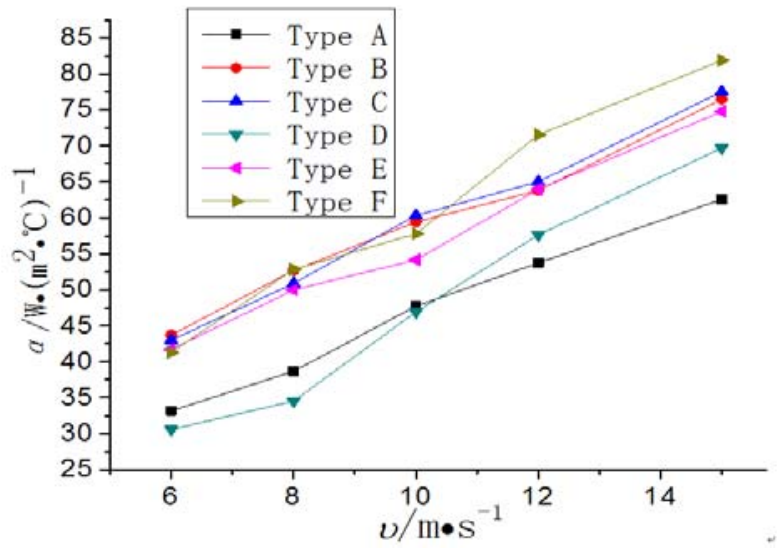

Figure 4. Relation between convective heat transfer coefficient $\alpha$ and air velocity $v$
- Pressure drop $\Delta p$

The relation between pressure drop $\Delta p$ and air velocity $\mathrm{v}$ is shown in Figure 5. With the same fin pitch, pressure drop $\Delta p$ increases with the increase of fin height and fin width, which is because the bigger fin suffers more friction.

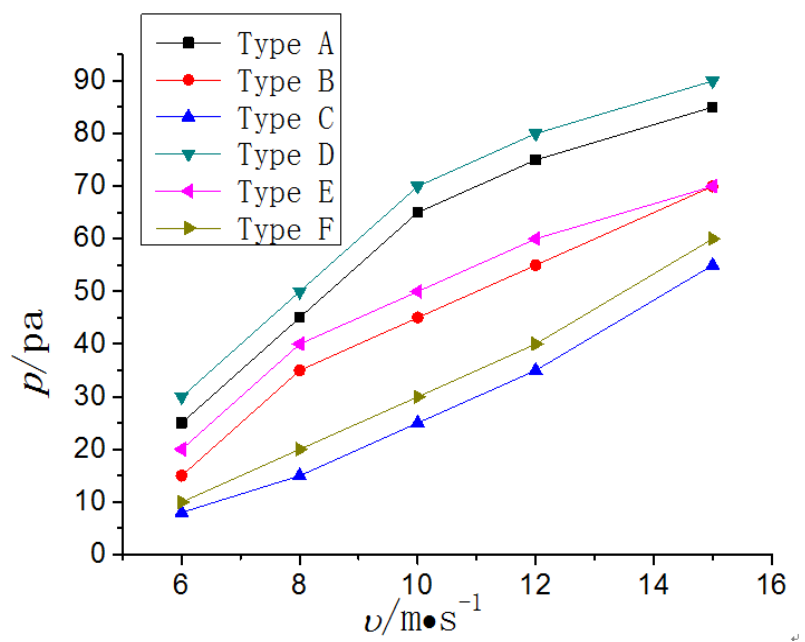

Figure 5. Relation between pressure drop $\Delta p$ and air velocity $v$

\section{B. Analysis of experimental results}

- Fin efficiency $\eta_{f}$

Fin efficiency is related to convective heat transfer coefficient $\alpha$, fin height $h_{1}$, fin width $h_{2}$ and fin thermal conductivity $\lambda$ :

$$
\eta=\phi\left(\alpha, h_{1}, h_{2}, \lambda\right)
$$

According to the experiments, fin efficiency is proportional to the air velocity but inversely proportional to fin height and fin width, so it can be expressed as:

$$
\eta_{\mathrm{f}}=f\left(\frac{h_{1}}{d}, \frac{h_{2}}{d}, v\right)
$$

$h 1, h 2$ and $v$ are independent factors, so Eqn. 6 can be written as:

$$
\eta_{\mathrm{f}}=P_{1} v^{P 2}\left(\frac{h_{1}}{d}\right)^{P 3}\left(\frac{h_{2}}{d}\right)^{P 4}
$$

TABLE II. EXPERIMENTAL DATA OF FIN EFFICIENCY $\eta$

\begin{tabular}{llllll}
\hline Air velocity & Type & Type & Type & Type & \multicolumn{2}{c}{ Type } \\
D $/ \mathrm{s}$ & A & B & C & Type & F \\
\hline 6 & 0.6955 & 0.6939 & 0.6946 & 0.6668 & 0.6608 \\
8 & 0.6866 & 0.6773 & 0.6798 & 0.6398 & 0.6429 \\
10 & 0.6826 & 0.6758 & 0.6709 & 0.6081 & 0.6264 \\
12 & 0.6775 & 0.6701 & 0.6639 & 0.5913 & 0.6407 \\
15 & 0.6497 & 0.6489 & 0.6511 & 0.5754 & 0.6252 \\
\end{tabular}


The experimental data of fin efficiency is shown is Table II. The data is composed of a number of independent factors. When processing these independent factors, the method of variable separation was taken to analyse their effects on fin efficiency. And the fitting correlation was obtained by nonlinear fitting method. The obtained coefficients P1, P2, P3 and P4 are 7.41, -0.116, -2.32 and 0.198. Then Eqn. 7 can be expressed as:

$$
\eta_{\mathrm{f}}=7.41 v^{-0.12}\left(\frac{h_{1}}{d}\right)^{-2.32}\left(\frac{h_{2}}{d}\right)^{-0.198}
$$

The correlation is suitable for: $v=6 \sim 15 \mathrm{~m} / \mathrm{s}$. Its relative error is $2.09 \%$.

- Convective heat transfer coefficient $\alpha$ and dimensionless criterion $\mathrm{Nu}$
According to theoretical analysis, convective heat transfer coefficient is related to air velocity, fin height, fin width, fin pitch and air properties:

$$
\alpha=\phi\left(v, h_{1}, h_{2}, P, \rho, \lambda, c_{p}, v\right)
$$

$v, h_{1}, h_{2}, P, \rho, \lambda, c_{p}$ and $v$ are independent factors. To facilitate data processing, Eqn. 9 was dimensionless analysed:

$$
N u=P_{1} \operatorname{Re}^{P_{2}}\left(\frac{d}{P}\right)^{P_{3}}\left(\frac{h_{1}}{P}\right)^{P_{4}}\left(\frac{h_{2}}{P}\right)^{P_{5}}
$$

Where $N u=\alpha l / \lambda ; R e=v l / v ; \alpha=$ convective heat transfer

\begin{tabular}{|c|c|c|c|c|c|c|}
\hline $\begin{array}{l}\text { Air velocity } \\
\mathrm{m} / \mathrm{s}\end{array}$ & $\begin{array}{l}\text { Type } \\
\text { A }\end{array}$ & $\begin{array}{l}\text { Type } \\
\text { B }\end{array}$ & $\begin{array}{l}\text { Type } \\
\text { C }\end{array}$ & $\begin{array}{l}\text { Type } \\
\text { D }\end{array}$ & $\begin{array}{l}\text { Type } \\
\text { E }\end{array}$ & $\begin{array}{l}\text { Type } \\
\text { F }\end{array}$ \\
\hline 6 & 33.18 & 43.69 & 43.01 & 30.57 & 41.75 & 41.31 \\
\hline 8 & 38.67 & 52.68 & 50.90 & 34.56 & 49.99 & 52.82 \\
\hline 10 & 47.73 & 59.43 & 60.32 & 46.94 & 54.16 & 57.77 \\
\hline 12 & 53.74 & 63.82 & 65.01 & 57.63 & 63.96 & 71.52 \\
\hline 15 & 62.60 & 76.48 & 77.53 & 69.70 & 74.81 & 81.88 \\
\hline
\end{tabular}
coefficient; and $l=$ qualitative dimension.

TABLE III. EXPERIMENTAL DATA OF CONVECTIVE HEAT TRANSFER COEFFICIENT $\alpha$

The experimental data of convective heat transfer coefficient $\alpha$ is shown in Table III, which is composed of some independent factors. When processing the independent factors, the method of variable separation was used to analyse their effects on convective heat transfer coefficient. Nonlinear fitting method was taken to process the experimental data to obtain the fitting correlation. The corresponding coefficients P1, P2, P3, P4 and P5 are 0.053, $0.756,-0.212,-0.294$ and 0.155 . Then Eqn. 10 can be expressed as:

$$
N u=0.053 \operatorname{Re}^{0.756}\left(\frac{d}{P}\right)^{-0.212}\left(\frac{h_{1}}{P}\right)^{-0.294}\left(\frac{h_{2}}{P}\right)^{0.155}
$$

The correlation is suitable for: $\mathrm{Re}=5000 \sim 18000$. The relative error of this correlation is $2.79 \%$.
- Resistance coefficient $E u$

According to Eqn. 4, resistance coefficient is related to air velocity and tube structure:

$$
E u=\phi(v, H)
$$

By dimensionless and separated variable method, Eqn. 12 can be turned into Eqn. 13:

$$
E u=P_{1} \operatorname{Re}^{P_{2}}\left(\frac{l}{\mathrm{~d}_{\mathrm{dl}}}\right)^{P_{3}}
$$

Fin height, fin width and air velocity are independent factors. To facilitate data processing, the dimensionless method was taken.

TABLE IV. EXPERIMENTAL DATA OF PRESSURE DROP

\begin{tabular}{lllllll}
\hline Air velocity & Type & Type & Type & Type & Type & Type \\
m/s & A & B & C & D & E & F \\
\hline 6 & 25 & 15 & 8 & 30 & 20 & 10 \\
8 & 45 & 35 & 15 & 50 & 40 & 20 \\
10 & 65 & 45 & 25 & 70 & 50 & 30 \\
12 & 75 & 55 & 35 & 80 & 60 & 40 \\
15 & 85 & 70 & 55 & 90 & 70 & 60 \\
\hline Unit: $\mathrm{Pa}$ & & & & & &
\end{tabular}

The experimental data of pressure drop is shown in Table IV .Nonlinear fitting method was used to process the experimental data to obtain the fitting correlation. The corresponding coefficients P1, P2 and P3 are 19.14, -0.57 and 1.3. Then Eqn. 13 can be expressed as:

$$
E u=19.14 \operatorname{Re}^{-0.57}\left(\frac{l}{\mathrm{~d}_{\mathrm{dl}}}\right)^{1.32}
$$

The correlation is suitable for: $\operatorname{Re}=5000 \sim 18000$. Its relative error is $3.7 \%$.

\section{CONCLUSIONS}

As air velocity $v$, fin height $h_{1}$ and fin width $h_{2}$ increase, fin efficiency $\eta_{\mathrm{f}}$ decreases. Its correlation derived is:

$$
\eta_{\mathrm{f}}=7.41 v^{-0.12}\left(\frac{h_{1}}{d}\right)^{-2.32}\left(\frac{h_{2}}{d}\right)^{-0.198}
$$


The correlation is suitable for: $v=6 \sim 15 \mathrm{~m} / \mathrm{s}$. The relative error of this correlation is $2.09 \%$.

Convective heat transfer coefficient $\alpha$ is proportional to fin pitch $P$ but inversely proportional to fin height $h_{1}$ and fin width $h_{2}$. The correlation of $N u$ is:

$$
N u=0.053 \operatorname{Re}^{0.756}\left(\frac{d}{P}\right)^{-0.212}\left(\frac{h_{1}}{P}\right)^{-0.294}\left(\frac{h_{2}}{P}\right)^{0.155}
$$

The correlation is suitable for: $\mathrm{Re}=5000 \sim 18000$. Its relative error is $2.79 \%$.

Pressure drop $\Delta p$ increases with the increase of fin height $h_{1}$ and fin width $h_{2}$. The correlation of $E u$ is:

$$
E u=19.14 \operatorname{Re}^{-0.57}\left(\frac{l}{\mathrm{~d}_{\mathrm{dl}}}\right)^{1.32}
$$

The correlation is suitable for: $\mathrm{Re}=5000 \sim 18000$. The relative error of this correlation is $3.7 \%$.

\section{REFERENCES}

[1] Y. Jin, G.H. Tang, Y.L. He \& W.Q. Tao, Parametric study and field synergy principle analysis of $\mathrm{H}$-type finned tube bank with 10 rows. International Journal of Heat and Mass Transfer, 60, pp.241-251, 2013.

[2] Tong Lu-hai, 3D numerical analysis of heat transfer characteristics for H-type finned tube. Mechanical \& Electrical Engineering Magazine, 152(24), pp.79-81, 2007.

[3] Zhang Zhi-xiang, Wang Yun-gang \& Zhao Qin-xin, Numerical Study on Performance Optimization of H-type Finned Tubes. Journal of Power Engineering, 30, pp. 941-946, 2010.

[4] Yu Xin-na, Yuan Yi-chao, Ma You-fu \& Liu Hai-lei, Experimental Tests and Numerical Simulation on Heat Transfer and Resistance Characteristics of H-type Finned Tube Banks. Journal of Power Engineering, 30, pp.433-438, 2010.

[5] Chen Han-Taw \& Lai Jian-Rong, Study of heat-transfer characteristics on the fin of two-row plate finned-tube heat exchangers. International Journal of Heat and Mass Transfer, 55(15-16), pp.4088-4095, 2012.

[6] Wu Xin, Shang Yu-wei, Wang Jun-long \& Ren Gang-lian, Experimental research heat transfer characteristics of H-type finned tube bundles. Journal of Southeast University (Natural Science Edition), 43(1), pp.88-93, 2013. 